This item was submitted to Loughborough's Research Repository by the author.

Items in Figshare are protected by copyright, with all rights reserved, unless otherwise indicated.

\title{
A critical review of the systems approach within patient safety research
}

PLEASE CITE THE PUBLISHED VERSION

\section{VERSION}

SMUR (Submitted Manuscript Under Review)

LICENCE

CC BY-NC-ND 4.0

\section{REPOSITORY RECORD}

Waterson, Patrick. 2019. "A Critical Review of the Systems Approach Within Patient Safety Research". figshare. https://hdl.handle.net/2134/5950. 
This item was submitted to Loughborough's Institutional Repository (https://dspace.lboro.ac.uk/) by the author and is made available under the following Creative Commons Licence conditions.

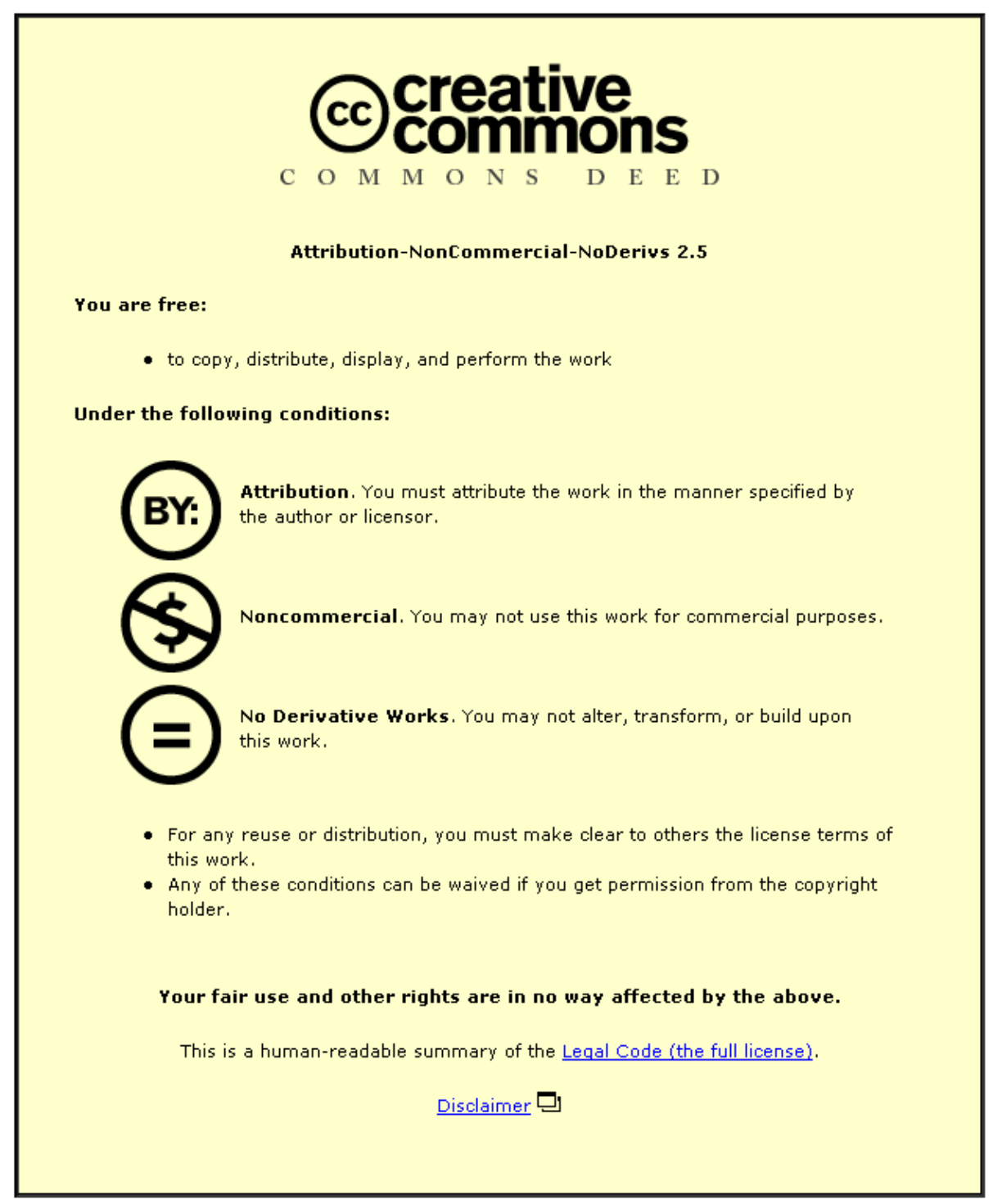

For the full text of this licence, please go to: http://creativecommons.org/licenses/by-nc-nd/2.5/ 


\section{Ergonomics}

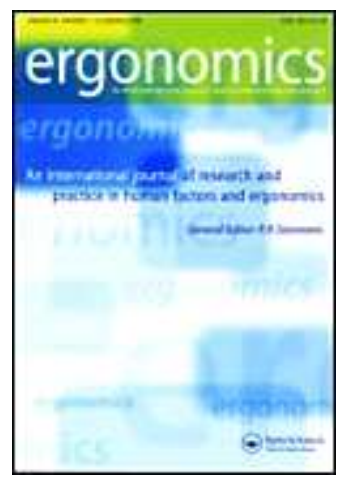

A Critical Review of the Systems Approach within Patient Safety Research

\begin{tabular}{|r|l|}
\hline Journal: & Ergonomics \\
\hline Manuscript ID: & draft \\
\hline Manuscript Type: & Review Article \\
\hline Date Submitted by the & n/a \\
\hline Complete List of Authors: & Waterson, Patrick; Loughborough University \\
\hline Keywords: & $\begin{array}{l}\text { work organisation < Organisational Ergonomics, health care } \\
\text { Organics }<\text { Application Domains, socio-technical systems }< \\
\text { Performance, patient safety < Health and Safety }\end{array}$ \\
\hline
\end{tabular}

\section{ScholarONE \\ Manuscript Central}


6

7

A Critical Review of the Systems Approach within Patient Safety Research

\author{
Patrick Waterson $^{1}$
}

Address for correspondence:

Dr. Patrick Waterson

Department of Human Sciences

Loughborough University

Loughborough, LE11 3TU,

United Kingdom.

Tel: 01509228478

Fax: 01509223940

\footnotetext{
${ }^{1}$ Email: p.waterson@lboro.ac.uk.
} 


\begin{abstract}
The application of concepts, theories and methods from systems ergonomics within patient safety has proved to be an expanding area of research and application in the last decade. This paper aims to take a step back and examine what types of research have been conducted so far and use the results to suggest new ways forward. An analysis of a selection of the patient safety literature suggests that research has so far focused on human error, frameworks for safety and risk, and incident reporting. The majority of studies have addressed system concerns at an individual level of analysis with only a few analysing systems across multiple system boundaries. Based on the findings it is argued that future research needs to move away from a concentration on errors and towards an examination of the connections between systems levels. Examples of how this could be achieved are described in the paper.
\end{abstract}

\title{
Statement of Relevance for Ergonomics Practice
}

The outcomes from the review of the systems approach within patient safety provide practitioners and researchers within health care (e.g., the UK NHS) with a picture of what types of research are currently being investigated, gaps in our understanding and possible future ways forward.

\section{Keywords}

Complex Systems; Sociotechnical Systems; Patient Safety; Health Care Ergonomics; Work Organisation. 


\section{The systems approach within ergonomics}

The use of the systems approach within ergonomics is well established (e.g., Singleton, 1974; Hendrick and Kleiner, 2002) and has been applied to a wide variety of application domains including aviation, rail transport and nuclear power (e.g., Reason, 1990; Wilson et al., 2007; Hollnagel et al., 2006). Chapanis (1996) defines a system as "an interacting combination, at any level of complexity, of people, materials, tools, machines, software, facilities and procedures designed to work together for some common purpose." The historical roots of the approach cut across a range of disciplines (e.g., cybernetics, organisational behaviour, risk management, psychology) and trace their origins to the work of von Bertalanffy (1950) on general systems theory, as well as the sociotechnical movement of the 1950's (Emery, 1959; Trist, 1959). A central idea of the approach is that complex systems, for example organisations, teams and types of technology, are composed of interrelated components, the properties of which are changed if the system is dissembled in any way (Katz and Kahn, 1966). In addition, adopting a systems ergonomic point of view often affords insights into how actions or occurrences at one level (e.g., an error made by a process operator) collectively interact with team (e.g., situation awareness) and organisational (e.g., safety culture) levels of analysis. In more recent years, the systems approach has staged something of a comeback and appears to be growing in popularity (e.g., Walker et al., 2008; Eason, 2008).

Defining the core components of the approach proves to be a difficult task since there appears to be no firm agreement amongst researchers. Other authors (e.g., Turner, 1978; Blockley, 1998) have attempted to be more specific and have included the following elements in their use of the approach (figure 1):

- Input-output processes - this relates to the stages that lead up to an accident or a disaster occurring (e.g., precipitating or trigger events), but also refers to the relationships that exist between inputs to a system and corresponding outputs. Multifinality in this context means that similar initial conditions can lead to different end effects.

- Whole-part relationships - the fundamental idea in this case is that in order to understand the functioning of the whole system one must first examine the parts 
(Gibson, 1979). It also follows on that the whole is more than the sum of the parts and that the relationship between these is dynamic and sometimes unpredictable or chaotic (Singleton, 1974; Sinclair, 2007).

- Connectivity between elements - system complexity arises from many simple interrelated processes that are highly connected. The principle of equifinality within general systems theory for example, states that the same result can be obtained with different types of inputs (e.g., rich/poor information as input to the system, depending on sub-processes - Katz and Kahn, 1966). The degree of coupling between system levels and components is also likely to have an impact upon the overall functioning of the system (Perrow, 1984).

Figure 1 about here

\subsection{The use of the systems approach within patient safety research}

Over the course of the last decade the application of human factors and ergonomics within the domain of patient safety has proved to be a huge growth area in terms of both research and application within healthcare settings. More recently, the use of systems and macroergonomic concepts, theories and approaches has attracted the interest of research groupings drawn from the medical profession (e.g., clinicians and other healthcare professionals), medical sociologists and psychologists, as well as ergonomists and human factors engineers. This growth is partly reflected in the growing number of papers and journal special issues covering patient safety that have appeared in recent years (e.g., Bagnara and Tartaglia, 2007; Salas et al., 2006; Edworthy et al., 2006). The systems approach has also gained in popularity through many reports in the press and championing by high profile individuals (e.g., Naik, 2006; Donaldson, 2007).

A number of models and frameworks have been proposed in order to organise and stimulate the development of theory and empirical research within the systems 
Figure 2 about here

These models of patient safety have much in common with the characteristics and components of the systems approach within ergonomics outlined above, in that they provide a basis for a broad coverage of system variables (e.g., individual issues, organisational factors) within the large health care system. Secondly, the models span a wide range of levels of analysis (e.g., organisational, social, individual), subcomponents (e.g., management decisions, technological factors) and linkages between these. These linkages are sometimes described as causal, or more usually contributory factors and are identified as selectively, or in combination, leading to an accident or adverse incident. 


\subsection{Motives and objectives of the review}

Alongside the many calls for the application of the systems approach to patient safety, a number of criticisms of its use have been made. Infante (2006) for example, states that most empirical work is carried out in the absence of explicit theoretical models and does not adequately address issues relating to the relationship between different levels of analysis and the actors within these (e.g., organisation-team interrelationships). Similarly, Hoff et al. (2004) in their review of the links between organisational factors, medical errors and patient safety, found that research has so far focused on a limited range of social and organisational factors. Others have argued that the drive toward patient safety and the application of the systems approach may have encouraged the medical profession to seek out short-term solutions (e.g., Wears, 2005), whereas the real benefits of the approach may take decades rather than months or years to realise. Finally, there is evidence to suggest that medical professionals are themselves confused by what is meant by the term "system" and "error" and the impact these have within the context of patient safety (Waring, 2007; Elder et al. 2006).

These criticisms, alongside the fact that the systems approach has over the years sometimes proved to be misinterpreted and misconstrued by those purporting to be using it (Ashmos and Huber 1987), motivated the present review. Specifically, the objectives are:

(1) To provide a better understanding, based upon an analysis of a selection of the patient safety literature, of the coverage of research purporting to adopt a systems approach - what has been so far the focus of research, how comprehensive is it, and what areas have not been addressed?

(2) To provide a better understanding of how research so far has addressed the issue of connectivity and causality between system components and levels of analysis

- how much research has looked at the issue of relationships between levels and system boundaries?

(3) To use the findings from (1) and (2) as a basis for identifying research gaps and ways forward that could be explored in the future. 


\section{Review approach}

In carrying out the review it was necessary to be selective about what types of publications could be judged to be adopting the systems approach within patient safety. In addition, the review aimed to cover research which could falls within the broad scope of ergonomics or human factors. The challenges involved in carrying out such a review largely relate to terminology and definition. The term "system" for example, has many different definitions (e.g., a technology, a method or technique, a biological entity). Likewise, system ergonomics is in itself broad in scope, covering research drawn from a wide variety of domains including many bordering mainstream ergonomics/human factors (e.g., organisation science, psychology, sociology), as well as different traditions and approaches within ergonomics (e.g., macroergonomics, sociotechnical systems theory). In order to overcome these problems it was decided to keep the analysis of publications as inclusive as possible at the beginning and then to filter out articles judged to be outside the scope of the systems approach to patient safety. This approach contrasts with other research which has used keywords and database filters at the outset, in order to review specific and relatively well-defined constructs (e.g., Tzeng and Yin, 2007).

\subsection{Identification and selection of publications}

A search was conducted on the PubMed and Ergonomics Abstracts databases for the years 1999-2007 using the keywords "system" and "patient safety". The year 1999 was taken as a starting point since many researchers regard the publication of the “To Err is Human" report in the United States (Kohn et al., 1999) as a landmark marking the beginning of modern patient safety research. PubMed and Ergonomics Abstracts were chosen for their coverage of literature relating to patient safety in medicine and ergonomics respectively. Search operators and wildcards were used in order to ensure that only publications using the terms system (or systems) and patient safety in titles, abstracts or keywords, were retrieved. A total of 4960 publications in total were retrieved (PubMed, $n=4875$, Ergonomics Abstracts, $\mathrm{n}=85)$.

A set of criteria were used to filter out articles from those retrieved from the databases. These included articles that focused on the following: 
- The use of techniques, procedures or methods that were judged to be primarily medical were not included (e.g., the use of a technique or procedure in surgery).

- The use of a technological system without explicitly referring to it's use within a safety context or providing data covering evaluation.

- Case studies which did not specify at least outline details of how, for example, a safety initiative was implemented, what data was gathered or what the outcomes from the initiative were.

- Legal or legislative aspects of patient safety.

- Calls for safety programs, the advantages of the systems approach or it's importance - many papers, particularly those published between 1999-2003, "championed" the systems approach without providing details relating to examples or data.

- Papers published in languages other than English.

Articles were content analysed and selected if they addressed an issue that was likely to fall within the broad range of subjects matter within ergonomics/human factors, whilst at the same time directly addressing patient safety.

\subsection{Framework for categorising publications}

The abstracts of each article was reviewed and then classified using Vincent et al's (1998) framework for contributory factors influencing clinical practice. As a result of carrying out this analysis it was decided to reorganise some of the elements of Vincent et al's framework. For example, the component "national health service executive" within the factor type "institutional context factors" is too specific to cover other types of health systems. The terms Health System (General) covering, for example, the UK NHS as well as US Healthcare systems and Health System (Local) covering hospital trusts and smaller geographical units (e.g., American states) were substituted. Similarly, many terms overlap in the Vincent et al. framework and for the purposes of the review were collapsed (e.g., knowledge and skills, competence). A number of other categories were added as a result of conducting the preliminary categorisation. For example, the category "safety and error" was added in order to cover the diversity and range of research using the 
systems approach to patient safety in this area. The final categorisation scheme with examples drawn from the literature search is shown in Table 1.

Table 1 about here

The review also categorised articles in terms of their coverage of broad levels of analysis within the larger system (i.e., inter-organisational, organisational, team and individual levels). The purpose of this analysis was to ascertain the number of articles that have attempted to cross boundaries between system levels and established links between them (e.g., organisation-team linkages). An analysis was also carried out of the types of medical domain (e.g., surgery, pharmacy) in which they were conducted.

\section{Findings}

A total of 360 papers were selected using the criteria, approximately $7.7 \%$ of the total number of articles yielded by the PubMed and Ergonomics Abstracts databases. A total of 289 articles were selected from the PubMed database and the remaining 71 from the Ergonomics Abstracts database.

\subsection{Coverage of research issues and health care domains}

The results of the analysis concerning the primary focus of publications are summarised as percentages of the total number of articles reviewed in figure 3 . The most frequent number of studies fell into the category of "Safety and Errors" ( $n=202,56 \%$ of all articles) with the subcomponents "errors" $(n=57)$ being most frequent, followed by "approaches/frameworks" $(n=48)$, "incident reporting" $(n=42)$, "safety/risk perceptions" $(n=33)$ and "safety culture" $(n=22)$.

Further analysis of the subcomponents showed that the majority of studies which focused on errors concentrated on individual errors $(n=47)$ as compared to errors made by healthcare teams $(n=10)$. It should be noted however, that it proved 
difficult in many instances to categorise, and distinguish between, articles using a distinction between individual/team errors. Similar problems occurred in trying to distinguish between individual and team safety/risk perceptions where the broad trend indicated that most research had focused on individual perceptions.

Figure 3 about here

The second most frequently occurring focus of study fell into the category "individual factors" $(\mathrm{n}=42.12 .7 \%$ of all articles $)$ with the subcomponents "training/education" $(\mathrm{n}=18)$ being the most frequent, followed by "workload/shiftwork" ( $n=14)$ and work design $(n=5)$. Articles within the category "change management" ( $\mathrm{n}=12,3.3 \%$ of all articles) focus on describing experiences implementing safety programmes within healthcare (e.g., setting up a quality management initiative). Within the category "technology and design" ( $n=36,11.9 \%$ of all articles), most articles focused on "system design" ( $n=12)$, followed by "patient labelling" and "design for safety" (each category $n=5$ ). Most of the articles in the category "team factors" ( $n=22,5.9 \%$ of all articles) have focused either on "communication" ( $n=10)$ or "team handover/transfer" $(n=7)$. Within the category "organisational and management" ( $n=23,6.6 \%$ of all articles) most articles focused on aspects of "structure/culture" $(n=13)$, with a few $(n=3)$ on "communication" and "management/governance". Finally, within the category "institutional context" ( $n=22,6.1 \%$ of all articles) most articles focused on the "health system (specific)" $(n=11)$ or the "health system (general)" $(n=10)$. Fewer articles focused on "economic/regulatory" issues $(\mathrm{n}=1)$.

The results of the analysis concerning the clinical domains which were investigated are summarised as percentages of the total number of articles reviewed in figure 4 .

Figure 4 about here 
Approximately half of the articles reviewed were carried out in hospitals and the various clinical specialisms which exist within hospitals $(n=206,57.2 \%$ of total). Articles which did not focus on a specific specialism (categorised as "general") made up the majority of these $(n=86)$. In terms of the specialisms a large proportion of the articles were within surgery $(n=54)$, followed by emergency/acute medicine $(n=20)$, pharmacy $(n=14)$, paediatrics $(n=11)$ and intensive care $(n=11)$. A smaller number of articles were reviewed within other clinical specialisms and patient groupings (e.g., psychiatry, outpatients). Within the category "General Medicine", a number of articles were categorised as focusing on the health system as a whole $(n=86)$, with fewer concentrating on local health systems $(n=11)$. Healthcare professional (e.g., nursing staff) make up the majority of articles in the category "Clinical Professions" $(n=28)$, followed by clinicians $(n=12)$, managers $(n=3)$ and other professions $(n=6)$.

\subsection{Coverage of system levels and boundaries}

The results of the analysis concerning coverage of the system are summarised as percentages of the total number of articles reviewed in figure 5. For the majority of articles reviewed it was not possible to identify what levels of the system were covered ( $n=123$ articles). Many articles presented general views on the relationship between system factors and patient safety (e.g., outlined a safety program or emphasised the importance of incident reporting without providing specific details). A similar comment should be made about the difficulties in categorising system coverage and levels during the analysis. In many cases it proved difficult to clearly identify publications focusing on solely on individual, team or organisational levels within the system. For this reason, the analysis presented here is an indication of trends, rather than a complete picture of systems coverage within the articles.

Figure 5 about here 
Most of the articles that could be identified as relevant to one particular system level concentrated on individuals ( $\mathrm{n}=98,27.2 \%$ of all articles). The next highest category were articles referring to the team level of analysis ( $n=62,17.2 \%$ of all articles), followed by the organisational level $(n=50,13.9 \%$ of all articles). A number of articles mentioned one or more levels of the system (i.e., multi-level, $n=22,6.1 \%$ of all articles). Few articles mentioned inter-organisational factors that may be involved in terms of the overall system ( $\mathrm{n}=5,1.4 \%$ of all articles).

\section{Discussion}

A number of themes can be picked out from the review, these include: the dominance of studies concentrating on human error and incident reporting; system coverage limitations; and, coverage of medical domains.

\subsection{Dominance of studies on human error and incident reporting}

The results of the literature review indicate that most of the research that has been so far carried out with systems and patient safety has concentrated on errors; the reporting of errors or safety/risk perceptions. In many respects this is unsurprising, with patient safety research placing a heavy emphasis upon the nature of errors and how best to manage and document them. However, what is perhaps more surprising is that adopting a systems approach to patient safety has not resulted in a more eclectic view of safety and error. Most of the articles focused on individual error, fewer on team errors and none on what might be labelled "organisational" errors. This could of course be due to limitations in the sampling procedure used to review articles. However, as outlined earlier on in the paper, adopting the systems approach usually means trying to gain some view of the larger picture and to think systemically rather than focus on one level within the system to the exclusion of others. The systems approach also attempts to understand the causes of error and the events that led up to it's occurrence (sometimes referred to as the "aetiology" of error). The review that was carried out concentrated on classification and obtaining approximate numbers of papers falling into the categorisation framework. Despite this, a more even distribution of articles in other categories in the framework was expected, particularly covering research issues that have been shown in other domains to be contributory factors within human error (e.g., similar percentages of articles, or at least higher percentages, covering aspects of individual and team 
communication). Other researchers have argued that the application of a systems approach towards safety issues needs to be sensitive to the social and organisational processes through which safe operation is created and maintained (Rochlin, 1999). Within patient safety research, Dekker (2007) suggested that there is a need to move beyond "error counting" and toward a better understanding of the links between errors and "the systematic, lawful connection between ... assessments and actions, and the tools, tasks and environment that surrounded them". The results of the literature review add some support for this point of view alongside some evidence that related topics such as organisational structure and culture, as well as safety culture, are being investigated. Perhaps the most important aspect of these findings is the limited number of factors linking these factors together and moving across levels as well as the boundaries between them (e.g., organisational-team linkages).

With regard to medical domains, hospitals proved to be the most popular domain of investigation. Most of the research conducted in hospitals was at a general level and either spanned a range of specialisms, wards or departments or did not directly report the background details of study participants. Studies involving surgery also feature prominently. The reason why surgery should prove to be such a fruitful area for research are not clear, possibly this is due to the complexity of the work, the degree of coordination between various specialisms (e.g., surgeons, anaesthetists, nurses) and its susceptibility to human error. Surgery is also sometimes seen as being the "apex" within healthcare organisations where the influence of decisionmaking is critical and organisational processes may have most impact.

Within the types of professions it is perhaps interesting that where a paper specified a profession, it was more likely to be nurses than doctors. Likewise, it is also worth noting that healthcare managers and administrators represented only a very small percentage of the types of professional roles studied. Within the UK NHS system the part played by managers and administrators in patient safety is crucial, as is the relationship these professions have with other healthcare professionals.

\subsection{Limited studies examining system boundaries and linkages between levels}

The results from the analysis of systems coverage also found that where a clear system level could be identified, most papers focused on individuals. Although team 
and organisational level investigations were carried out, few papers addressed issues across system levels or boundaries and even fewer reported interorganisational system interactions. The picture that emerges is one in which research has so far not looked in detail at the dynamics that exists across system boundaries and the interconnections that link decisions, policies and change in general at one level, with other levels of analysis. The reports from healthcare accidents and errors demonstrate that the way in which various system levels and components interact and how failures can "trickle down" from one level leading eventually to the occurrence of an adverse event (e.g., National Patient Safety Agency, 2001; Healthcare Commission, 2007). It is perhaps surprising then that more research has not followed up these linkages, particularly since cross-level system analyses are common in other related domains (e.g., rail systems ergonomics - Wilson et al., 2007; Santos-Reyes and Beard, 2006). One possible explanation is that this type of research is difficult to carry out and requires a longitudinal study design, multiple data collection methods and often involves the use of specialist statistical techniques (e.g., structural equation modelling). However, there are many good examples of management research on hospitals for example, that have spanned a number of levels of analysis and yielded interesting findings tracing through these levels and attempting to unpick the various interdependencies between them (e.g., Edmondson, 1996; Tucker, Nembhard and Edmondson, 2007; Zohar et al., 2007). There is a need to plug this gap in our understanding and for more of this type of research within patient safety to be undertaken in the future.

\section{Summary, conclusions and ways forward}

The results of the review provide a mixed picture of the systems approach to patient safety. The research so far appears to provide only partial coverage of the range and scope of issues we might we expect using a systems ergonomics approach. Likewise, few studies appear to provide details of the connections that exist between different system levels. Given the amount of papers that use the term "systems approach", as compared to those that cite research deriving from systems theory, sociotechnical systems or ergonomics, there is reason to believe that term "systems" is being used rhetorically and one might conjecture, inappropriately. The systems approach in patient safety research is still relatively new as compared to other domains and industries. In addition, it is clear that a certain degree of confusion and 
ambiguity surrounds the constructs, concepts and methods associated with the systems approach. In short, there is no one prescribed systems approach, rather there are a set of shared characteristics and components (Figure 1). Within these, however, there is broad scope for a variety of applications within healthcare. In the final section of the paper a brief example from patient safety (infection control) is described in order to illustrate a way of looking at healthcare systems that aims to extend the coverage and connectivity of the systems approach, whilst embodying some of the common characteristics associated with the approach (figure 1).

\subsection{Extending coverage and connectivity - an example from infection control}

Infection outbreaks within hospitals have recently grabbed the attention of the general public and the media in the UK (e.g., The Guardian, 2007; BBC Panorama, 2008). Partly because of this, they are now recognised as a central patient safety priority for health care systems within the UK and worldwide (Allegranzi et al., 2007). A recent review of the human, as compared to epidemiological or microbiological factors involved in infection control (Griffiths et al., 2008), demonstrates the wide variety of ergonomic issues that could be addressed by future research (Table 2). These issues go well beyond a focus on human error alone and extend the coverage of systems ergonomics issues to include a wide range of social and organisational issues in patient safety. The important point here is not that human error is irrelevant in this context, in may cases it may play an important role (e.g., the failure of an individual to follow hand washing guidelines), instead, error needs to viewed in a wider light and subject to wider scale, or macro, system influences and factors.

Table 2 about here

The issues of how these influences or factors might be connected together can be illustrated with reference to the Maidstone and Tunbridge Wells NHS Trust Clostridium difficile (C.diff.) outbreak. As a result of the outbreak an estimated 90 
people died after being infected with C.diff.. The 2007 report from the Healthcare Commission on the outbreak at the trust revealed a complex set of social, organisational and technical factors that contributed to the spread of C.diff. (Healthcare Commission, 2007). Figure 6 is an adaptation of Rasmussen's (1997) risk management framework to describe some of the range of factors that were involved in the outbreaks (Waterson, 2008).

Figure 6 about here

One way in which the connectivity between the various system levels in figure 6 could be investigated is by adopting the strategy of "bracketing" across system levels (Hackman, 2003). This involves carrying out conceptual and empirical analyses of constructs that exist in two or more system levels. Karsh (2006) has argued the case for something similar and uses the term "mesoergonomics" to describe: "an open system approach to the development of macroergonomic theory and research whereby the relationship between variables in at least two different levels or echelons are studied, and one of the variables is a macroergonomic outcome of interest such as performance, stress, injury, technology acceptance or quality of worklife" (p. 3). In the case of infection outbreaks this might mean carrying out studies that investigate the impact upon infection control rates of macro level system factors (e.g., targets for bed occupancy set by the government and implemented through strategic health authorities and NHS trusts) upon meso level factors (e.g., leadership style). In other cases, it might involve studying the mesomicro system levels in the light of infection rates (e.g., the interaction between leadership/management styles and levels of job satisfaction). These types of crosslevel investigations offer the potential to provide researchers and practitioners with better accounts of whole-part relationships, the connectivity between system elements (figure 1), as well as helping to scope interventions aimed at redesign or intervention (Karsh and Brown, 2008). 
Word Count: (without figures) $=4,743$ explanation across multiple system levels.

Government reports repeatedly cite the importance of a "whole systems" approach and all indications are that this is likely to increase, rather than decrease in importance (e.g., Healthcare Commission, 2008). The systems approach has the potential to play a major role in helping to make health care safer. If this is to be achieved, and the full benefits of the approach are to be exploited, then researchers need to extend their coverage of system issues and expand their powers of 


\section{References}

Allegranzi, B. Storr, J., Dziekan, G., Leotsakos, A., Donaldson, L. and Pittet, D. (2007), The first global patient safety challenge "Clean Care is Safer Care" from launch to current progress and achievements. Journal of Hospital Infection, 65 (supplement 2): 15 .

Apker, J., Mallak, L.A. and Gibson S.C. (2006), Communicating in the "gray zone": perceptions about emergency physician hospital handoffs and patient safety. Academic Emergency Medicine, 14, 10, 884-94.

Ashmos, D.P. and Huber, G.P. (1987), The systems paradigm in organization theory: Correcting the record and suggesting the future. Academy of Management Review, 12, 4, 607-612.

Bagnara, S. and Tartaglia, R. (2007), Patient safety - an old and a new issue. Theoretical Issues in Ergonomics Science, 8, 5, 365-369.

Balka, E., Doyle-Waters, M., Lecznarowicz, D. and Fitzgerald, J.M. (2007), Technology, governance and patient safety: Systems issues in technology and patient safety. International Journal of Medical Informatics, 76, 1, 35-47.

Barenfanger, J., Sutter, R.L., Lang, D.L., Collins, S.M., Hacek, D.M. and Peterson, L.R. (2004), Improving patient safety by repeating (read-back) telephone reports of critical information. American Journal of Clinical Pathology, 12, 1, 6, 801-3.

Battles, J.B., Dixon, N.M., Borotkanics, R.J., Rabin-Fastmen, B. and Kaplan, H.S. (2006), Sensemaking of patient safety risks and hazards. Health Services Research, $41,4: 2,1555-75$.

BBC Panorama (2008), How Safe is Your Hospital? (Broadcast on 27 $7^{\text {th }}$ April, 2008), (available at:

http://www.bbc.co.uk/mediaselector/check/player/nol/newsid_7370000/newsid_737 1100? redirect=7371116.stm\&news=1\&nbram=1\&nbwm =1\&bbram $=1 \& b b w m=1$ accessed $28^{\text {th }}$ April, 2008) 
Blockley, D. (1998), Managing proneness to failure. Journal of Contingencies and Crisis Management, 6, 2, 76-75.

Blough, C.A. and Walrath, J.M. (2007), Improving patient safety and communication through care rounds in a paediatric oncology outpatient clinic. Journal of Nursing Care and Quality, 22, 2, 159-63.

Brand, C., Ibrahim, J., Bain, C., Jones, C. and King, B. (2007), Engineering a safe landing: engaging medical practitioners in a systems approach to patient safety. Internal Medicine Journal, 37, 5, 295-302.

Broom, M., Slater, J. and Ure, D.S. (2006), An observational study of practice during transfer of patients from anaesthetic room to operating theatre. Anaesthesia, $61,10,943-5$.

Brown, A.D., Alikhan, L.M. and Seeman, N.L. (2006), Crossing the strategic synapse: aligning hospital strategy with shared system priorities in Ontario, Canada. Health Care Management Review, 31, 1, 34-44.

Brown, Y., Neudorf, K., Poitras, C. and Rodger, K. (2007), Unsafe student clinical performance calls for a systematic approach. Canadian Nurse, 103, 3, 29-32.

Buckle, P., Clarkson, P.J., Coleman, R., Ward, J. and Anderson, J, (2006), Patient safety, systems design and ergonomics. Applied Ergonomics, 37, 4, 491-500.

Carayon, P. and Alvarado, C.J. (2007), Workload and patient safety among critical care nurses. Critical Care Nursing Clinics of North America, 19, 2, 121-9.

Carayon, P., Hundt, A.S., Karsh, B.T., Gurses, A.P., Alvarado, C.J., Smith, M. and Brennan, P.F. (2006), Work system design for patient safety: The SEIPS model. Quality and Safety in Health Care, 15 (Suppl. I), 50-58. 
Catchpole, K.R., Giddings, A.E., Wilkinson, M., Hirst, G., Dale, T. and de Leval, M.R. (2007), Improving patient safety by identifying latent failures in successful operations. Surgery, 142, 1, 102-10.

Chapanis, A. (1996). Human Factors in Systems Engineering. New York: John Wiley \& Sons, Inc.

Clarke, J.R. (2006), How a system for reporting medical errors can and cannot improve patient safety. American Surgeon, 72, 11,1088-91

De La Fuente, J. and Bix, L. (2005), Applying universal design to child resistant packaging. Proceedings of Include 2005, London 5-8 April, Royal College of Art, London, CD-ROM, 11.

Dekker, S. (2007), Doctors are more dangerous than gun owners: A rejoinder to error counting. Human Factors, 49, 2, 177-184.

DePalma, R.G. (2006), Surgical quality programs in the Veterans Health Administration. American Surgeon, 72, 11, 999-1004.

Donaldson, L. (2007), Safety First in 21st Century Healthcare, Public Lecture given by the UK Chief Medical Officer, Loughborough University $1^{\text {st }}$ February 2007.

Durbin, J., Hansen, M.M., Sinkowitz-Cochran, R. and Cardo, D. (2006), Patient safety perceptions: a survey of Iowa physicians, pharmacists, and nurses. American Journal of Infection Control, 34, 1, 25-30.

Eason, K.D. (2008), Before the internet: the relevance of socio-technical systems theory to emerging forms of virtual organisation. Manuscript submitted for publication.

Edmondson, A.C. (1996), Learning from mistakes is easier said than done: group and organization influences on the detection and correction of human error. Journal of Applied Behavioral Science 32, no. 1, 5-28. 
Edworthy, J., Hignett, S., Hellier, E. and Stubbs, D. (2006) Editorial: Special issue on Patient Safety. Ergonomics, 49, 439-443.

Emery, F.E. (1959), Characteristics of socio-technical systems. The Tavistock Institute of Human Relations, January 1959, Document No. 527.

Elder, N.C., Pallerla, H. and Regan, S. (2006), What do physicians consider an error? A comparison of definitions and physician perception. BMC Family Practice, $7,73,1-9$.

Evans, S.M., Berry, J.G., Smith, B.J., Esterman, A., Selim, P., O'Shaughnessy, J. and DeWit, M. (2006), Attitudes and barriers to incident reporting: a collaborative hospital study. Quality and Safety in Health Care, 15, 1, 39-43

Frush, K.S. and Alton, M. (2006), Development and implementation of a hospitalbased patient safety program. Pediatric Radiology, 36, 4, 291-8.

Galvin, L., McBeth, S., Hasdorff, C., Tillson, M. and Thomas, S. (2007), Medication bar coding: to scan or not to scan? Computing, Informatics and Nursing, $25,2,86-92$.

Gibson, J. J. (1979) The Ecological Approach to Visual Perception. Boston, MA:Houghton Mifflin.

Gluck, P.A. (2007), Patient safety in women's health care: a framework for progress. Best Practice and Research Clinical Obstetrics and Gynaecology, 21, 4, 25-36.

Grant, M.J., Donaldson, A.E. and Larsen, G.Y. (2006), The safety culture in a children's hospital. Journal of Nursing Care and Quality, 21, 3, 223-9.

Gregory, D.M., Guse, L.W., Dick, D.D. and Russell, C.K. (2007), Patient safety: where is nursing education? Journal of Nursing Education, 46, 2, 79-82.

Griffiths, P., Renz, A. and Rafferty, AM. (2008), The impact of organisation and 
management factors on infection control in hospitals: a scoping review. Kings College,London.

(http://www.kcl.ac.uk/content/1/c6/04/08/39/Infectioncontrolreport.pdf, accessed $15^{\text {th }}$ September, 2008).

The Guardian (2007), Deadly superbug infections widespread in UK hospitals, says expert. The Guardian newspaper, October $11^{\text {th }} 2007$.

Gurses, A.P. and Carayon, P. (2007), Performance obstacles of intensive care nurses. Nursing Research, 56, 3, 185-94.

Hackman, J.R. (2003), Learning more by crossing levels: evidence from airplanes, hospitals, and orchestras. Journal of Organizational Behaviour, 24, 905-922.

Healthcare Commission (2007), Investigation into outbreaks of Clostridium difficile at Maidstone and Tunbridge Wells NHS Trust.

http://www.healthcarecommission.org.uk/_db/_documents/Maidstone_and_Tunbrid ge_Wells_investigation_report_Oct_2007.pdf (accessed October 10th 2007).

Healthcare Commission (2008), Not just a matter of time: a review of urgent and emergency care services in England.

http://www.healthcarecommission.org.uk/serviceproviderinformation/reviewsandstu dies/servicereviews/ahpmethodology/urgentcare.cfm (accessed October 1st 2008).

Helmreich, R.L. and Sexton, J.B. (2004), Managing threat and error to increase safety in medicine. In R. Dietrich and K. Jochum (Eds.), Teaming Up: Components of Safety under High Risk. Aldershot: Ashgate.

Hendrick, H.W. and Kleiner, B.M. (2002, Eds.), Macroergonomics: Theory, Methods and Applications. London : Lawrence Erlbaum Associates

Hoff, T., Jameson, L. Hannan, E. and Flink, E. (2004), A review of the literature examining linkages between organizational factors, medical errors and patient safety. Medical Care Research and Review, 61, 1, 3-37. 
Hollnagel, E., Woods, D. D., and Leveson, N. (Eds.) (2006). Resilience Engineering: Concepts and Precepts. London: Ashgate

House, R., Rousseau, D.M. and Thomas-Hunt, M. (1995), The meso paradigm: a framework for the integration of micro and macro organizational behaviour. Research in Organizational Behaviour, 17, 71-114.

Infante, C. (2006), Bridging the "system's" gap between interprofessional care and patient safety: Sociological insights. Journal of Interprofessional Care, 20, 5, 517525.

Johnsson, C., Kjellberg, K. And Lagerstrom, M. (2004), A direct observation instrument for assessment of nurses' patient transfer technique (DINO). Applied Ergonomics, 35, 6, 615.

Karsh, B-T. (2006). Meso-ergonomics: a new paradigm for macroergonomics research. Proceedings of the International Ergonomics Association 2006 Congress.

Karsh, B-T. and Brown, R. (2008) Macroergonomics and patient safety: the impact of levels on theory, measurement, analysis and intervention in medical error research. Manuscript submitted for publication.

Katz, D. and Kahn, R. (1966), The Social Psychology of Organizations. New York: Wiley.

Kiekkas, P., Brokalaki, H, Manolis, E., Samios, A., Skartsani, C. and Baltopoulos, G. (2007), Patient severity as an indicator of nursing workload in the intensive care unit. Nursing and Critical Care, 12, 1, 34-41.

King, T. and Byers, J.F. (2007), A review of organizational culture instruments for nurse executives. Journal of Nursing Administration. 37, 1, 21-31. 
Kohn, L., Corrigan, J. and Donaldson, M.E. (1999), To Err is Human. Washington, DC: National Academy Press.

Landry, M.D. and Sibbald, W.J. (2002), Changing physician behavior: a review of patient safety in critical care medicine. Journal of Critical Care, 17, 2, 138-45.

Leonard, M., Graham, S. and Bonacum, D. (2004), The human factor: the critical importance of effective teamwork and communication in providing safe care. Quality and Safety in Healthcare, 13, Suppl. 1, 85-90.

Lin, L. and Liang, B.A. (2007), Addressing the nursing work environment to promote patient safety. Nursing Forum, 42, 1, 20-30.

Lingard, L., Espin, S., Whyte, S. Regehr, G., Baker, G.R., Reznick, R., Bohnen, J. , Orser, B, Doran, D. and Grober, E. (2004) Communication failures in the operating room: an observational classification of recurrent types and effects. Quality and Safety in Healthcare, 13, 5, 330-4.

Lee, A.C., Leung, M. And So, K.T. (2007), Managing patients with identical names in the same ward. International Journal of Health Care Quality Assurance, 18, 1, 1523

McLoughlin, V., Millar, J., Mattke, S., Franca, M., Jonsson, P.M., Soemkh, D. and Bates, D. (2006), Selecting indicators for patient safety at the health system level in OECD countries. International Journal of Quality and Health Care, 18, Suppl 1, 1420.

Moody, L.E., Slocumb, E., Berg, B. and Jackson, D. (2004), Electronic health records documentation in nursing: nurses' perceptions, attitudes, and preferences. Computing Informatics and Nursing, 22, 6, 337-44.

Morath, J.M. (2006), Patient safety: a view from the top. Pediatric Clinician North America, 53, 6, 1053-65. 
Naik, G. (2006), A hospital races to learn lessons of Ferrari pit stop. Wall Street Journal, November $14^{\text {th }} 2006$.

National Patient Safety Agency (2001), External Inquiry into the Adverse Incident that occurred at Queens Medical Centre, Nottingham, $4^{\text {th }}$ January 2001. http://www.archive.npsa.nhs.uk/site/media/documents/824_toftqueensmedical.pdf (accessed March 30th 2007).

Nowinski, C.V. and Mullner, R.M. (2006) Patient safety: solutions in managed care organizations? Quality and Management in Health Care, 15, 3, 130-6.

Perneger, T.V. (2005), The Swiss cheese model of safety incidents: are there holes in the metaphor? BMC Health Services Research, 5, 71, 1-7.

Perrow, C. (1984), Normal Accidents: Living with High-Risk Technologies. New York: Basic Books.

Reason, J.T. (2001a), A systems approach to organizational error. Ergonomics, 38, 8, 1708-1721.

Reason, J.T. (2001b), Understanding adverse events: the human factor. In C. Vincent (Ed.), Clinical Risk Management: Enhancing Patient Safety, $2^{\text {nd }}$ Edition. London: BMJ Publications..

Reason, J.T., Carthey, J. and de Leval, M.R. (2001), Diagnosing "vulnerable system syndrome": an essential prerequisite to effective risk management. Quality and Safety in Healthcare, 10 (Suppl. II), 2, 21-25.

Rochlin, G.I. (1999), Safe operation as a social construct. Ergonomics, 42, 11, 1549-1560.

Rose, J.S., Thomas, C.S., Tersigni, A., Sexton, J.B. and Pryor, D. (2006), A leadership framework for culture change in health care. Joint Commission Journal on Quality and Patient Safety, 32, 8, 433-42. 
Salas, E., Baker, D., King, H. and Battles, J. (2006), Special section commentary: Opportunities and challenges for human factors and ergonomics in enhancing patient safety. Human Factors, 48, 1, 1-4.

Santos-Reyes, J. and Beard, A.N. (2006), A systemic analysis of the Paddington railway accident. Proceedings of the Institute of Mechanical Engineering, Part F:J, Rail and Rapid Transit., 220, 121-151.

Scalise, J. (2006), Clinical communication and patient safety. $\underline{\text { Hospitals and Health }}$ Networks. 80, 8, 49-54.

Seiden, S.C. and Barach, P. (2006), Wrong-side/wrong-site, wrong-procedure, and wrong-patient adverse events: Are they preventable? Archives of Surgery, 141, 9, 931-9.

Sinclair, M.A. (2007), Ergonomics issues in future systems. Ergonomics, 50, 12, 1957-1986.

Singleton, W.T. (1974), Man-Machine Systems. Penguin Books: Harmondsworth.

Stone, P.W., Mooney-Kane, C., Larson, E.L., Horan, T., Glance, L.G., Zwanziger, J. and Dick, A.W. (2007), Nurse working conditions and patient safety outcomes. Medical Care, 45, 6, 571-8.

Tartaglia, R., Belandi, T. And Albolino, S. (2006), Organising patient safety: The experience of the Tuscany's clinical risk management centre. Paper presentation $16^{\text {th }}$ World Congress of the International Ergonomics Association, Maastricht, The Netherlands.

Trist, E.L. (1959), Socio-technical systems. The Tavistock Institute of Human Relations, January 1959, Document No. 572. 
Tucker, A.L., Nembhard, I.M. and Edmondson, A.C. (2007), Implementing new practices: An empirical study of organizational learning in hospital intensive care units. Management Science, 53, 6, 894-907.

Turner, B. (1978), Man-Made Disasters. London: Wykeham Publications.

Tzeng, H-M. and Yin, C-Y. (2007), No safety, no quality - synthesis of research on hospital and patient safety (1996-2007). Journal of Nursing Care and Quality, 22, 4, 299-306.

United States Department of Health and Human Services (2000). Blood Safety Transcripts. Advisory Committee on Blood Safety and Availability, $11^{\text {th }}$ meeting. (http://www.hhs.gov/bloodsafety/transcripts/20000425.html). Accessed $12^{\text {th }}$ November 2007.

Vincent, C. (2005), Patient Safety. London: Churchill-Livingstone.

Vincent, C., Taylor-Adams, S. and Stanhope, N. (1998), Framework for analyzing risk and safety in clinical medicine. British Medical Journal, 316, 1154-1157.

Vogus and Sutcliffe, K. (2007), The impact of safety organizing, trusted leadership, and care pathways on reported medication errors in hospital nursing units. Medical Care, 45, 10, 997-1002.

Vrendenburgh, A.G. and Weiniger, M.B. (2004), Communication of drug hazard information: A critical analysis of the relationship between the pharmaceutical industry, FDA, Clinicians, and patients, and the impact on patient safety. Proceedings of the Human Factors and Ergonomics Society $48^{\text {th }}$ Meeting, New Orleans Louisiana, Conference Proceedings, 2040-2044.

Walker, G.H., Stanton, N.A., Salmon, P.M. and Jenkins, D.P. (2008), A review of sociotechnical systems theory: a classic concept for new command and control paradigms. To appear in Theoretical Issues in Ergonomics Science. 
Walsh, K. and Jiju, A. (2007) Improving patient safety and quality: what are the challenges and gaps in introducing an integrated electronic adverse incident and recording system within the health care industry? International Journal of Health Care Quality Assurance, 20, 2-3,107-15.

Waring, J.J. (2007), Doctors' thinking about the "system" as a threat to patient safety. Health: An Interdisciplinary Journal for the Study of Health, Illness and Medicine, 11, 1, 29-46.

Waterson, P.E. (2008), Systems analysis for infection control in acute hospitals. Manuscript submitted for publication.

Wears, R.L. (2005), Keep the celebrations short. Quality and Safety in Healthcare, $14,154$.

Weissman, J.S., Annas, C.L., Epstein, A.M., Scheider, E.C., Claridge, B., Kirle, L., Gatsonis, C., Feibelmann, S. and Ridley, N. (2005), Error reporting and disclosure systems: views from hospital leaders. JAMA - The Journal of the American Medical Association, 16, 293, 11, 1359-66.

Westfall, J.M., Fernald, D., Staton, E.W., VanVorst, R., West, D. and Pace, W.D. (2004), Applied strategies for improving patient safety: a comprehensive process to improve care in rural and frontier communities. Journal of Rural Health, 20, 4, 35562.

Wilson, J.R., Farrington-Darby, T., Bye, R. and Hockey, G.R.J. (2007), The railway as a socio-technical system: Human factors at the heart of successful rail engineering. Proceedings of the Institute of Mechanical Engineering, Part F, 221, 1, 101-116.

Yule, S. Flin, R., Paterson-Brown, S, Maran, N. and Rowley, D. (2006), Development of a rating system for surgeons' non-technical skills. Medical Education, 40, 11, 1098-104. 
Zohar, D., Livne, Y., Tenne-Gazit, O., Admi, H. and Donchin, Y. (2007), Healthcare climate: a framework for measuring and improving patient safety. Critical Care Medicine, 35, 5, 1. 


\section{List of figures and tables}

Figure 1: Characteristics and components of the systems approach

Figure 2: A model of organisational accident causation within patient safety (adapted from Vincent, 2005)

Figure 3: Primary focus of study: Bar chart of percentage of articles in each category

Figure 4: Medical domain: Bar chart of percentage of articles in each category

Figure 5: Systems coverage: Bar chart of percentage of articles in each category

Figure 6: Example of the systems approach applied to the Maidstone and Tunbridge Wells NHS Trust Clostridium difficile outbreak

Table 1: Review categorisation scheme

Table 2: Examples of systems ergonomics issues associated with infection control (summary based on Griffiths et al., 2008) 
Figure 1: Characteristics and components of the systems approach

Figure 2: A model of organisational accident causation within patient safety (adapted from Vincent, 2005)

Figure 3: Primary focus of study: Bar chart of percentage of articles in each category

Figure 4: Medical domain: Bar chart of percentage of articles in each category

Figure 5: Systems coverage: Bar chart of percentage of articles in each category

Figure 6: Example of the systems approach applied to the Maidstone and Tunbridge Wells NHS Trust Clostridium difficile outbreak 
Multifinality -

alternative goals can

be attained from the

same inputs

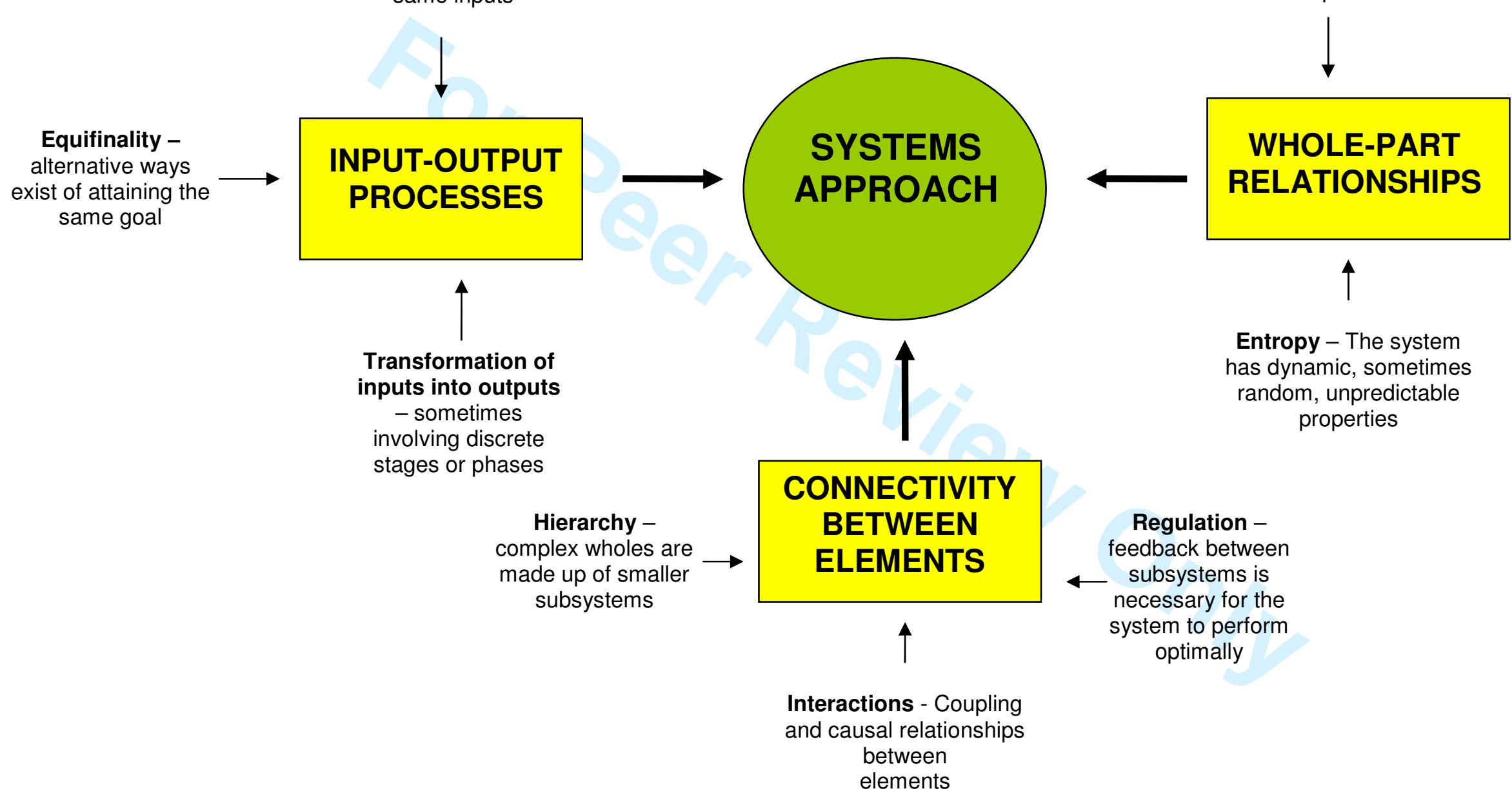

Holism - the whole is

more than the sum of

its parts

System elements -

independent

elements which

cannot be viewed in isolation

Figure 1: Characteristics and components of the systems approach 
Figure 2: A model of organisational accident causation within patient safety (adapted from Vincent, 2005)

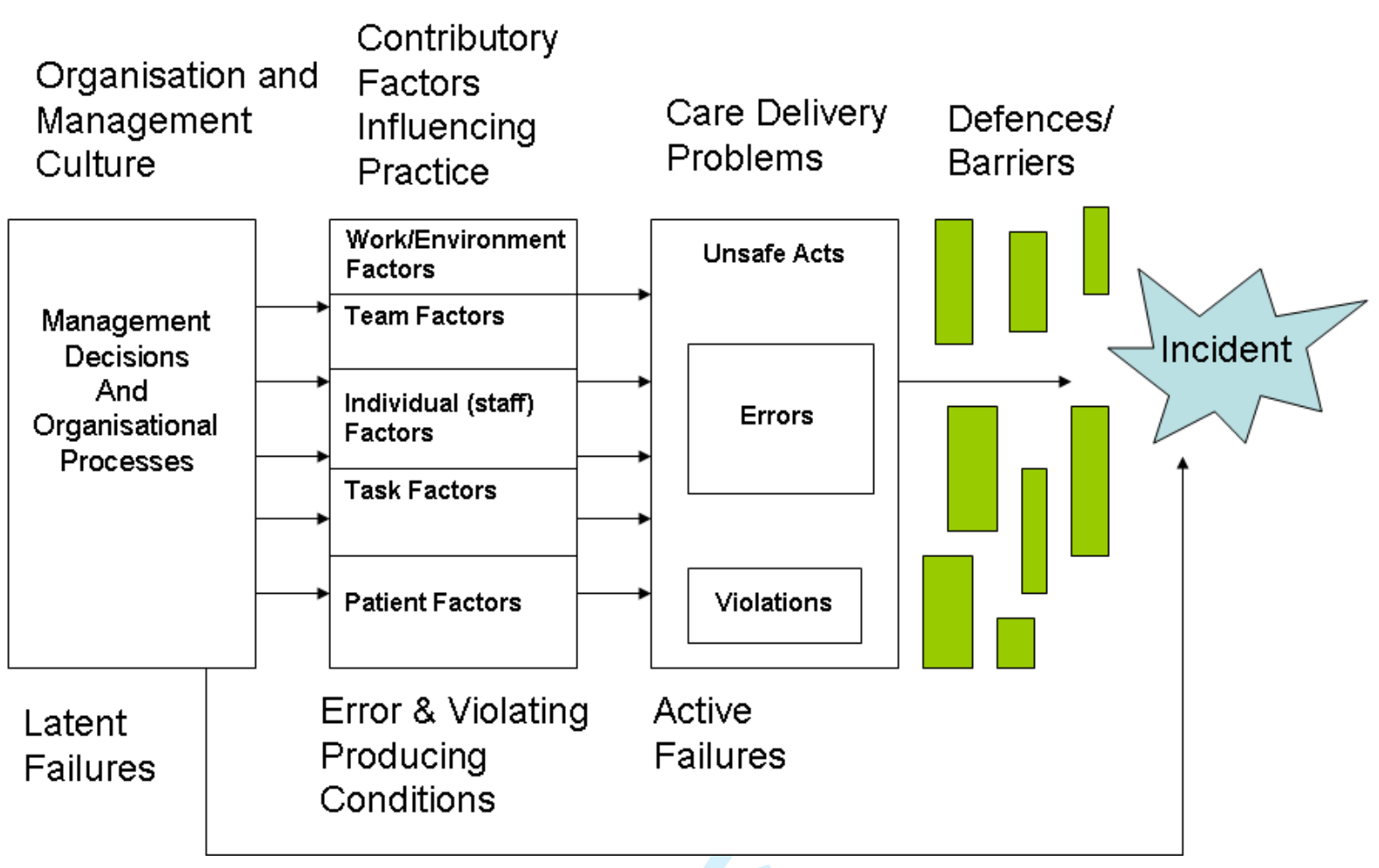


Figure 3: Primary focus of study: Bar chart of percentage of articles in each category

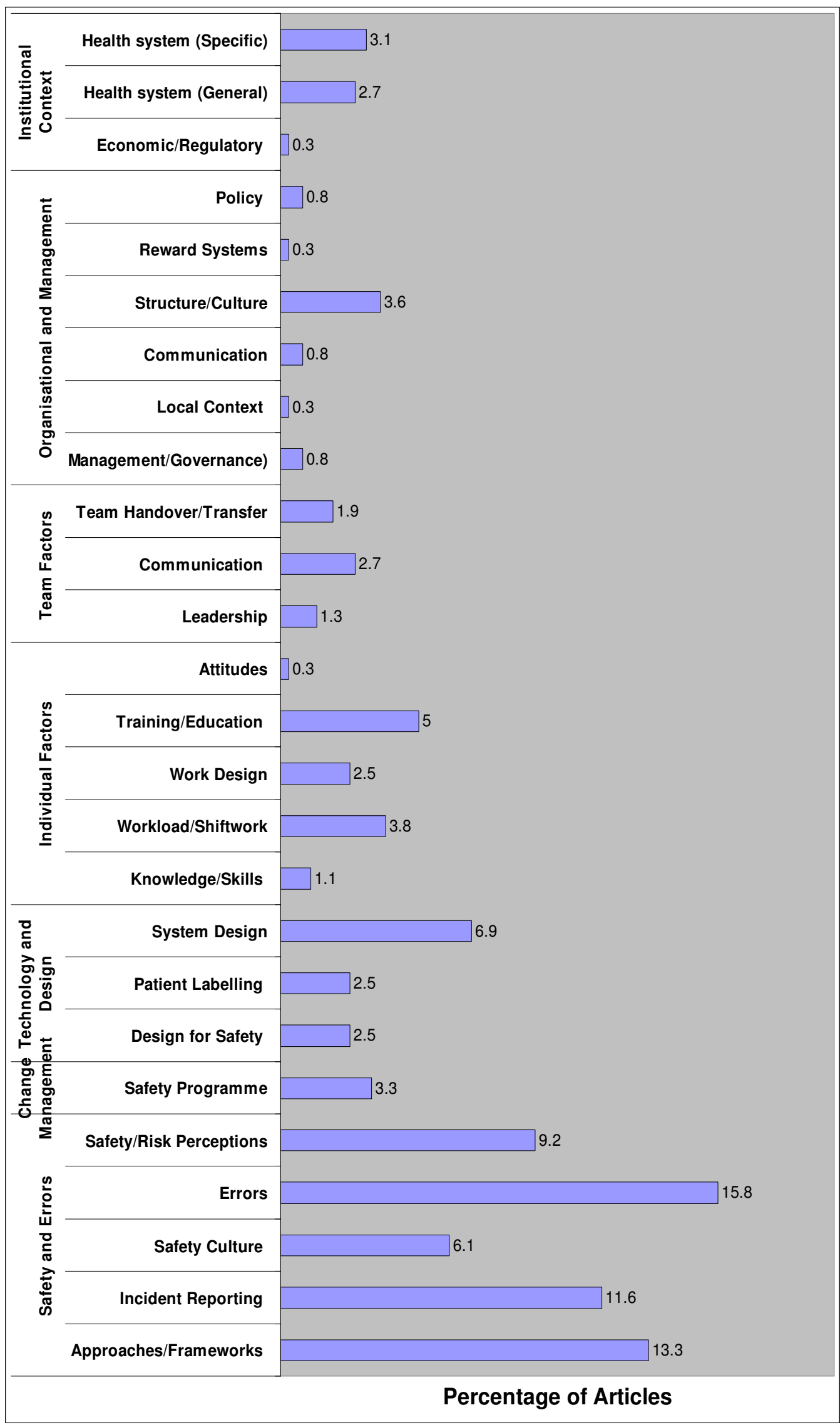


Figure 4: Medical Domain; Bar chart of percentage of articles in each category

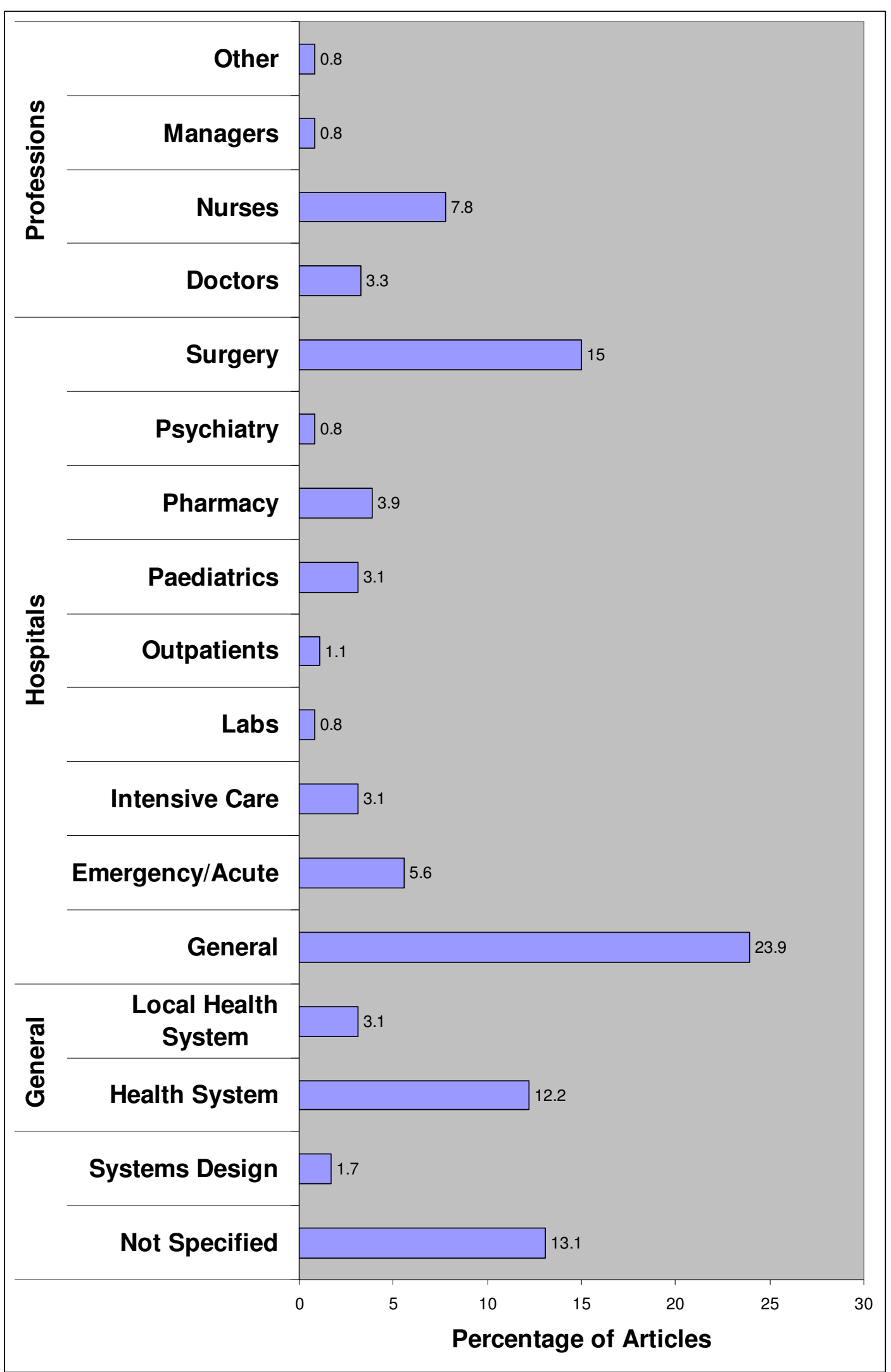


Figure 5: Systems coverage: Bar chart of percentage of articles in each category

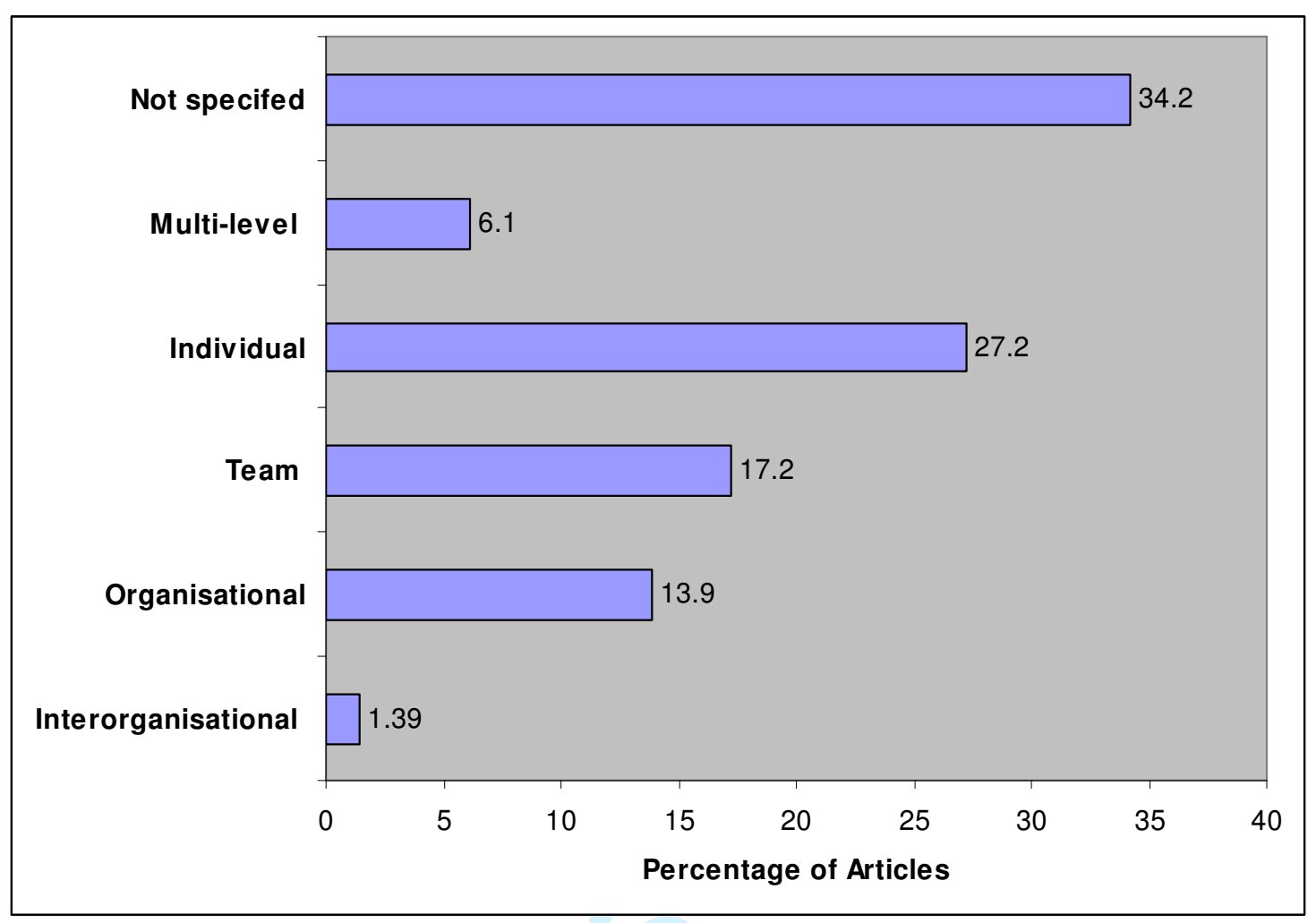


Figure 6: Example of the systems approach applied to the Maidstone and Tunbridge Wells NHS Trust Clostridium difficile outbreak

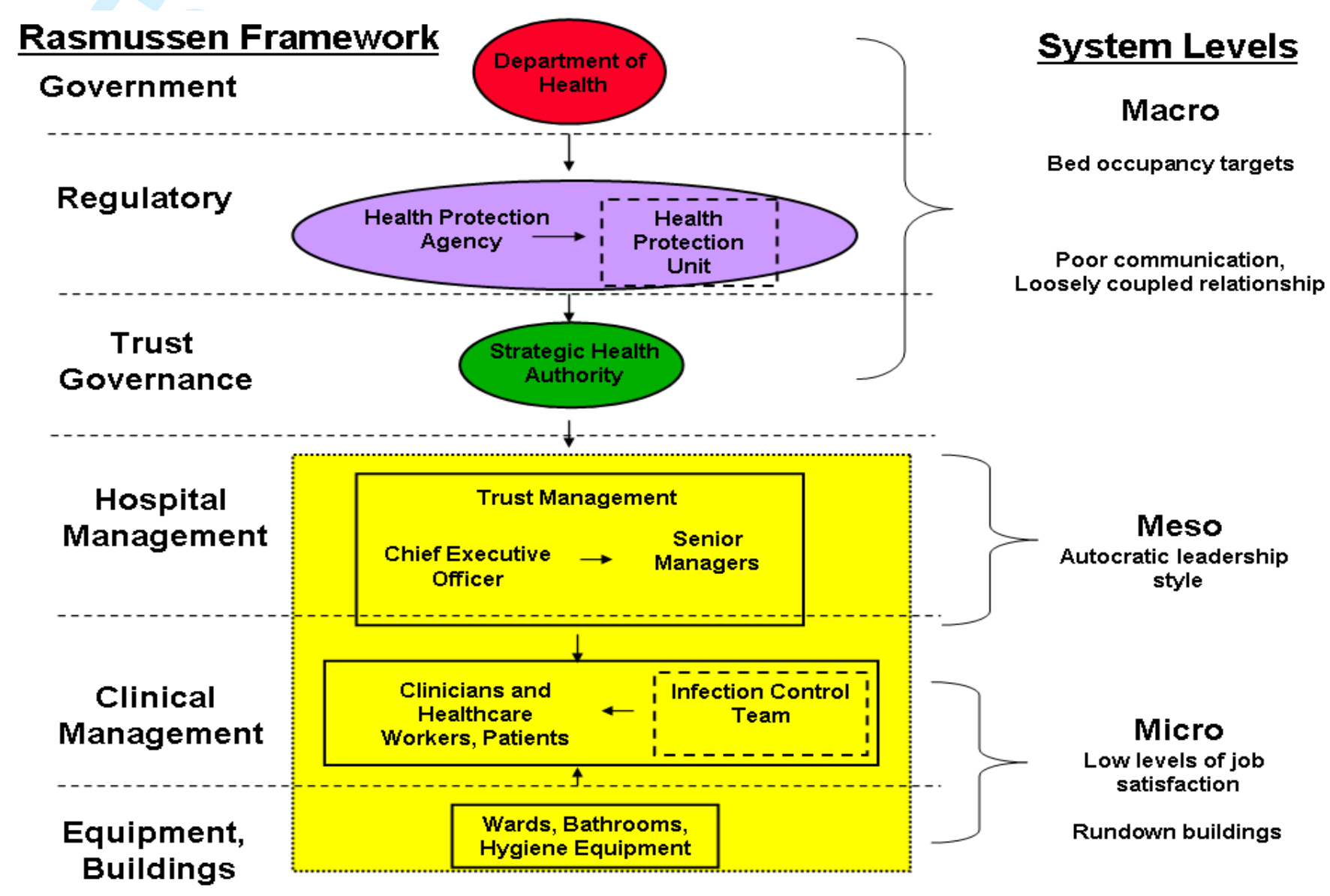




\section{List of tables}

Table 1: Review categorisation scheme

Table 2: Examples of systems ergonomics issues associated with infection control (summary based on Griffiths et al., 2008) 
Table 1: Review categorisation scheme

\begin{tabular}{|c|c|c|}
\hline Category & Subcomponents & Examples \\
\hline \multirow[t]{3}{*}{ Institutional context } & Economic/Regulatory & $\begin{array}{l}\text { Communication between representatives from industry, clinicians and patients (Vrendenburgh and Weiniger, } \\
\text { 2004) }\end{array}$ \\
\hline & Health system (General) & $\begin{array}{l}\text { Nationally-based healthcare systems (e.g., Walsh and Jiju, 2007), general patient groups in the healthcare system } \\
\text { (e.g., women - Gluck, 2007) }\end{array}$ \\
\hline & Health system (Specific) & $\begin{array}{l}\text { Application of patient safety to specific medical domains (e.g., , paediatrics, general surgery - DePalma, 2006), } \\
\text { types of specific healthcare (e.g., rural Westfall et al., 2004). }\end{array}$ \\
\hline \multirow[t]{6}{*}{$\begin{array}{l}\text { Organisational and } \\
\text { management }\end{array}$} & Management/Governance & $\begin{array}{l}\text { Frameworks for leadership of safety culture programs (Rose et al., 2006). Leadership perspectives on error } \\
\text { reporting (Weissman et al., 2005) }\end{array}$ \\
\hline & $\begin{array}{l}\text { Local Organisational } \\
\text { Context }\end{array}$ & Patient safety in a local geographical context (e.g. region - Tartaglia et el., 2006) \\
\hline & Communication & $\begin{array}{l}\text { Verbal communication of critical information (Barenfanger et al., 2004), general clinical communication (Scalise, } \\
\text { 2006) }\end{array}$ \\
\hline & $\begin{array}{l}\text { Organisational } \\
\text { Structure/Culture }\end{array}$ & Instruments for organisational culture (King and Byers, 2007) \\
\hline & Reward Systems & Introduction of performance-related pay and impact upon patient safety (Nowinski and Mullner, 2006) \\
\hline & Policy & Selecting patient safety indicators for the OECD countries (McLoughlin et al., 2006) \\
\hline \multirow[t]{3}{*}{ Team factors } & Leadership & $\begin{array}{l}\text { The impact of trusted leadership upon medical errors (e.g., Vogus and Sutcliffe, 2007); Requirements for } \\
\text { leadership within patient safety (Morath, 2006) }\end{array}$ \\
\hline & Communication & $\begin{array}{l}\text { Using care rounds as a means of improving communication between ward personnel (Blough and Walrath, 2007); } \\
\text { communication failures in the operating room (Lingard et al., 2004); use of surgical briefings to improve } \\
\text { communication (Leonard et al. 2004) }\end{array}$ \\
\hline & Team Handover/Transfer & $\begin{array}{l}\text { Techniques for the observation of patient handover (Johnsson et al., 2004); transfer from anaesthetic room to } \\
\text { operating theatre (Broom et al., 2006); perceptions of communication difficulties in handover (Apker et al., 2007). }\end{array}$ \\
\hline \multirow[t]{5}{*}{ Individual factors } & Knowledge/Skills & $\begin{array}{l}\text { Development of measure for non-technical skills (Yule et al., 2006); knowledge about the systems approach } \\
\text { (Waring, 2007). }\end{array}$ \\
\hline & Workload/Shiftwork & $\begin{array}{l}\text { Nursing workload in intensive care (Kiekkas et al., 2007); workload amongst nurses in critical care (Carayon and } \\
\text { Alvarado., 2007); working condition of nurses and safety outcomes (Stone et al., 2007) }\end{array}$ \\
\hline & Work Design & $\begin{array}{l}\text { Performance obstacles and work design in nursing (Gurses and Carayon, 2007); staff-patient ratios in nursing (Lin } \\
\text { and Liang, 2007) }\end{array}$ \\
\hline & Training/Education & $\begin{array}{l}\text { Need for educational support to instruct the systems approach (Brand et al., 2007; Brown et al., 2007); patient } \\
\text { safety education for the nursing profession (Gregory et al., 2007) }\end{array}$ \\
\hline & Attitudes & Changing the attitudes of doctors towards patient safety (Landry and Sibbald, 2002) \\
\hline
\end{tabular}

URL: http://mc.manuscriptcentral.com/terg E-mail: ergonomics@tandf.co.uk 


\begin{tabular}{|l|l|l|}
\hline \multicolumn{1}{|c|}{ Category } & \multicolumn{1}{|c|}{ Subcomponents } & \multicolumn{1}{c|}{ Examples } \\
\hline \multirow{5}{*}{ Technology and design } & Design for Safety & $\begin{array}{l}\text { Designing for patient safety and ergonomics (Buckle et al., 2006); design of packaging for patient safety (De La } \\
\text { Fuente and Bix, 2005) }\end{array}$ \\
\cline { 2 - 3 } & Patient Labelling & $\begin{array}{l}\text { Practical recommendations for patient barcoding (Galvin et al., 2007); Naming and barcoding of patients (Lee et } \\
\text { al., 2007) }\end{array}$ \\
\cline { 2 - 3 } Change management & $\begin{array}{l}\text { Sociotechnical and systems issues in system design (Balka et al., 2007); perceptions and views on electronic } \\
\text { records (Moody et al., 2004) }\end{array}$ \\
\hline Safety and Errors & Implementation of a safety & $\begin{array}{l}\text { Implementing a patient safety initiative within a geographical region (Brown et al., 2006); implementing patient } \\
\text { safety within a hospital (Frush and Alton, 2006) }\end{array}$ \\
\cline { 2 - 3 } & Approaches/Frameworks & $\begin{array}{l}\text { Sensemaking as an approach for understanding patient safety (Battles et al., 2006); Frameworks for understanding } \\
\text { human error and patient safety (Helmreich and Sexton, 2004). }\end{array}$ \\
\cline { 2 - 3 } & Safety Culture & $\begin{array}{l}\text { Improving patient safety using incident reports (Clarke, 2006); Attitudes toward incident reporting (Evans et al., } \\
\text { 2006) }\end{array}$ \\
\cline { 2 - 3 } & Errors & $\begin{array}{l}\text { Organisational safety climate in nursing (Zohar et al., 2007); safety culture in a children's hospital (Grant et al., } \\
\text { 2006) }\end{array}$ \\
\cline { 2 - 3 } & Safety/Risk Perceptions & $\begin{array}{l}\text { Latent failures in surgery (Catchpole et al., 2007); analysis of wrong site surgery (Seiden and Barach, 2006) } \\
\text { (Durbin et al., 2006) }\end{array}$ \\
\hline
\end{tabular}


Table 2: Examples of systems ergonomics issues associated with infection control (summary based on Griffiths et al., 2008)

\begin{tabular}{|c|c|}
\hline $\begin{array}{c}\text { Issue } \\
\end{array}$ & Sub-issues \\
\hline Leadership styles & $\begin{array}{l}\text { - Impact of positive and "laissez faire" leadership styles on } \\
\text { staff and patient satisfaction } \\
\text { - Rate of management turnover } \\
\text { - Extent of bullying and harassment by managers } \\
\text { - Number of staff being supervised by managers ("span of } \\
\text { control") }\end{array}$ \\
\hline $\begin{array}{l}\text { Management } \\
\text { structure and roles }\end{array}$ & $\begin{array}{l}\text { - Implementation of specific role (e.g., modern matron) } \\
\text { - Extent of role conflict and tensions } \\
\text { - Role clarity and ambiguity } \\
\text { - } \quad \text { Role overload }\end{array}$ \\
\hline Teamwork & $\begin{array}{l}\text { - Team make up (e.g., members from multiple disciplines) } \\
\text { - Team functioning and outcomes }\end{array}$ \\
\hline $\begin{array}{l}\text { Human resource } \\
\text { management }\end{array}$ & $\begin{array}{l}\text { - Extent and nature of staff appraisals } \\
\text { - Training policies and adequacy of training provision }\end{array}$ \\
\hline Clinical governance & $\begin{array}{l}\text { - Transparency of auditing, feedback and accountability } \\
\text { - } \quad \text { Degree of rick management focus }\end{array}$ \\
\hline $\begin{array}{l}\text { Workforce and } \\
\text { workload }\end{array}$ & $\begin{array}{l}\text { - Staffing and skill mix } \\
\text { - Team stability, turnover and use of temporary staff } \\
\text { - Job satisfaction and morale }\end{array}$ \\
\hline
\end{tabular}

